\title{
326 Monitoring and Adaptive Control of Cutting Forces Based on Spindle Motor and Servo Motor Currents in Machining Centers
}

\author{
Hidenori Saraie', Masahiro Sakahira' ${ }^{2}$, Soichi Ibaraki ${ }^{2}$, \\ Atsushi Matsubara', Yoshiaki Kakino ${ }^{2}$, and Makoto Fujishima ${ }^{1}$ \\ ${ }^{1}$ Technology R\&D, Mori Seiki, 201 Midai, Iga-cho, Ayama-gun, Mie 519-1414, Japan \\ E-mail: saraie@moriseiki.co.jp \\ ${ }^{2}$ Department of Precision Engineering, Kyoto University, Sakyo-ku, Kyoto 606-8501, Japan \\ E-mail: kakino@prec.kyoto-u.ac.jp
}

\begin{abstract}
Summary
For the intelligent manufacturing by a machining center, the authors have proposed an extension of fixed cycles to end milling processes in our previous works. For the enhancement of machining productivity, the extension of tool life, and the improvement of machining accuracies, we have proposed a scheme to optimize machining parameters within such a fixed cycle based on the regulation of cutting forces by using the initial machining database. In continuous machining, cutting forces gradually increase as the tool wear progresses. Therefore, it is crucial to perform a more reliable process control by continuously monitoring the cutting force. It is, however, unfavorable to install an additional sensor to monitor cutting forces from the viewpoint of the cost, reliability, and maintainability. To address this issue, this paper presents a scheme to estimate cutting forces by monitoring spindle and servo motor currents, along with a kinematic parameter defined by the geometrical interference between a tool and a workpiece.
\end{abstract}

Keywords: End milling, Fixed Cycles, Cutting Force Control, Tool Wear, Monitoring of Cutting Forces, Adaptive Control

\section{Introduction}

Fixed cycles are commonly used in drilling or tapping processes. Our research group on the intelligent manufacturing by flexible machine tools such a machining center has proposed the extension of fixed cycles, such as spiral and trochoid cycles, to end milling processes. The authors presented a scheme to optimize machining parameters in such a fixed cycle in order to enhance the machining productivity, to extend a tool life, and to improve machining accuracies ${ }^{(1)(2)(3)}$. In our previous works, we employed an optimization scheme of tool paths (the radial depth of cut) or the feedrate in order to regulate the cutting force to a desired constant level. The optimization is based on a mathematical model to predict cutting forces; it can be seen as a feedforward control scheme in a sense. The prediction model is given from a machining database. In continuous machining, however, cutting forces gradually increase as the tool wear progresses. Therefore, a reliable estimation of cutting forces is quite difficult by using the prediction model that is given at the beginning of the machining.

In this paper, we present a monitoring scheme of cutting forces such that the cutting force can be adaptively regulated on-line under a relatively slow variation of cutting forces caused by, for example, the tool wear. Taking a straight side milling as an example, the feasibility and effectiveness of the monitoring and control schemes of cutting forces are investigated.

\section{Cutting Force Monitoring Schemes}

2.1 Estimation of Cutting Forces by Monitoring Spindle and Servo Motor Currents

In this paper, we present a scheme to estimate cutting forces by monitoring spindle and servo motor currents, along with the cutting engagement angle that is a kinematic parameter defined by the geometrical interference between a tool and a workpiece.

Figure 1 illustrates a geometrical relationship of a tool and a workpiece in a straight side milling. The tangential component of the cutting force, $F_{l}$, is given by the spindle's output torque, $T_{s p}$, as follows:

$$
F_{t}=T_{s p} \times 1000 / r
$$

In operations where one of the axes is not moving, it is harder to estimate the cutting force in the direction of the non-moving axis by monitoring a servo motor current, since the non-moving axis is subject to a larger friction on guideway's. For example, in Figure 1 , the $x$-axis component of the cutting force, $F$, is more difficult to estimate from a servo motor current than its $y$-axis component, $F_{y}$. If the engagement angle, $\alpha_{e n}$, is known, however, it can be estimated by combining 1) the estimation of the cutting force in the moving axis direction. $F$, from the y-axis servo motor current. and 2) the estimation of the tangential component of cutting force, $l \%$, from the spindle motor current.

From $F \%$ and $\alpha_{i m}$, the normal cutting force. $F_{m}$, and the cutting force in the non-moving axis direction, lir. can be computed as follows: 


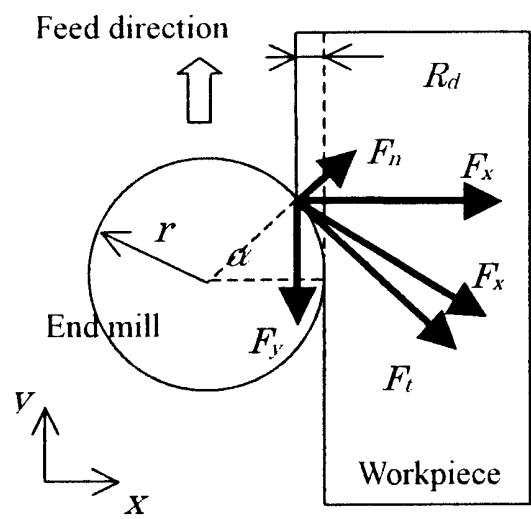

$F_{y}$ : Cutting force in the moving-axis direction [N]

$F_{x}$ : Cutting force in the non-moving-axis direction

$F_{x y}$ : Combined cutting force in the X-Y plane $[\mathrm{N}]$

$F_{t}$ : Tangential cutting force $[\mathrm{N}]$

$F_{n}:$ Normal cutting force $[\mathrm{N}]$

$\alpha_{e n}$ : Cutting engagement angle [rad]

$R_{d}:$ Radial depth of cut $[\mathrm{mm}]$

$r$ : Tool radius $[\mathrm{mm}]$

Figure 1 Cutting forces in a straight side milling (toward the $+y$ direction)

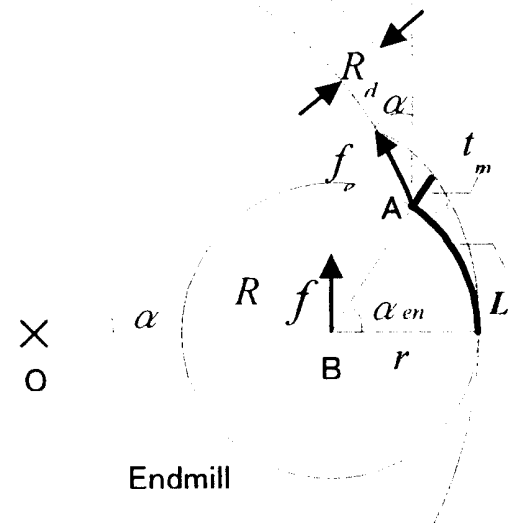
$t_{m}$ : the maximum undeformed chip thickness, mm $a_{e n}$ : the engagement angle, rad $f:$ the feed per tooth at the tool center. mm/tooth $f_{e}$ : the feed per tooth at the engagement point, $\mathrm{mm} /$ tooth $a$ : the angle between the directions of $f$ and $f_{a}, \mathrm{rad}$ $L$ : the arc length of cutting engagement, $\mathrm{mm}$ $R_{d}:$ the radial depth of cut, min $R$ : the arc radius of machined surface, $\mathrm{mm}$ $r$ : the tool radius, $\mathrm{mm}$

Figure 2 A schematic view of side milling

$$
\left\{\begin{array}{l}
F_{n}=\left(F_{y}+F_{t} \cdot \cos a_{e n}\right) / \sin \alpha_{e n} \\
F_{x}=\left(F_{y} \cdot \cos \alpha_{e n}+F_{t}\right) / \sin \alpha_{e n}
\end{array}\right.
$$

\subsection{A Prediction Model of Cutting Forces}

Figure 2 illustrates a geometrical interference of a tool and a workpiece in end milling processes. From the figure, the following equations can be derived:

$$
\begin{aligned}
& L=r \cdot \alpha_{e n} \\
& t_{m}=f \cdot \sin \left(\alpha_{e n}\right)
\end{aligned}
$$

Otsuka et al. ${ }^{4(5)}$ presented a prediction model of cutting forces by using a second-order response surface model on two machining parameters shown above. The second-order response surface model is generally given by:

$$
Y=C_{0}+C_{1} X_{1}+C_{2} X_{2}+C_{11} X_{1}^{2}+C_{22} X_{2}^{2}+C_{12} X_{1} X_{2}
$$

where $X$ represents input variables, and $Y$ represents the estimate. In the cutting force prediction model, $X_{I}$ and $X_{2}$ respectively represent $t_{m}$ and $L$, normalized by some central values.

In our previous works, the authors presented an off-line optimization scheme of machining parameters by using a database of the process model above, which was identified by pre-machining tests on the given workpiece and tool ${ }^{(1)(2)(3)}$. This scheme showed a satisfactory performance as long as the model guarantees a satisfactory prediction performance. In practical applications, particularly for flexible machine tools such as a machining center, it is impossible to provide a full database that covers every possible combination of machining processes. tools, and workpieces. Furthermore, in a continuous machining. cutting forces gradually increase due to the progress of tool wear. Therefore, it is in practice difficult to perform a high-accuracy prediction of cutting forces by using the initial database only. 
Table 1 Major specifications of the machining center

\begin{tabular}{c|c}
\hline Travel $(\mathrm{X} / \mathrm{Y} / \mathrm{Z})(\mathrm{mm})$ & $610 / 510 / 460$ \\
\hline Spindle motor output $(\mathrm{kW})[15 \mathrm{~min} /$ continuous $]$ & $18.5 / 15$ \\
\hline Rated output of servo motors $(\mathrm{kW})$ & 4.5 \\
\hline Maximum spindle speed $\left(\mathrm{min}^{-1}\right)$ & 20,000 \\
\hline Tool shank & $\mathrm{BT} 40$ \\
\hline Maximum rapid and cutting traverse speeds $(\mathrm{m} / \mathrm{min})$ & 42 \\
\hline Type of guideways & Liner guideway \\
\hline CNC unit & $\mathrm{M}-65$ \\
\hline
\end{tabular}

Table 2 Common Cutting Conditions

\begin{tabular}{c|c}
\hline Workpiece & Carbon steel (S50C) \\
\hline Tool & Solid carbide end mill with four flukes, $\phi 10 \mathrm{~mm}$ \\
\hline Tool extension, $\mathrm{mm}$ & 35 \\
\hline Spindle speed, $\mathrm{min}^{-1}$ & 2800 \\
\hline Axial depth of cut, $A_{d,} \mathrm{~mm}$ & 10 \\
\hline Milling method & Down cut \\
\hline
\end{tabular}

Table 3 Cutting conditions in monitoring tests

\begin{tabular}{c|c}
\hline Feedrate, $\mathrm{mm} / \mathrm{min}$ & $250,500,1000,1500,2000$ \\
\hline Radial depth of cut, $R_{d,} \mathrm{~mm}$ & $0.15,0.3,0.5,0.75,1.0,1.5,2.0,3.0$ \\
\hline
\end{tabular}

Assuming the application in a small-lot, large-variety production, we propose a tool wear detection scheme based on on-line monitoring and adaptive control of cutting forces. By monitoring the cutting force during the machining, its increase from the initial level (with a new tool) is detected in the form of the tool wear coefficient, which is independent of cutting conditions. By using this scheme, the tool wear can be detected even when an adaptive control of cutting forces is performed.

Let $Y_{m w}$ represent the cutting force estimated by using Eq. (5) when a new tool is used. In continuous machining, the cutting force generally increases as the tool wear progresses. Denote the estimated cutting force by $Y$. Suppose that they are related by:

$$
Y=\left(1+W_{f}\right) \cdot Y_{n e w}
$$

An increase of the cutting force due to the progress of tool wear is represented by an increase in the tool wear coefficient, $W_{f}$. Clearly, $W_{f}=0$ when the machining starts with a new tool. As $W_{f}$ increases, one must reduce the radial depth of cut, or the feedrate, in order to regulate the cutting force at a constant level. When the tool is subject to an excessive tool wear, it often causes chipping at a tool edge. If $W_{t}$ exceeds some threshold, one must judge that the end of tool life is reached, and exchange the tool.

3. Experimental Setup and Procedures

3.1 Experimental Setup

For the calibration of the cutting force estimation system, a high-accuracy tool dynamometer ( 5007 by Kistelr, Inc.) is used to measure the cutting force. It is compared with the estimated value by using internal sensors. Major specifications of the machining center used throughout the experiments are shown in Table 1 .

\subsection{Cutting Conditions for Monitoring Tests}

Table 2 shows experimental conditions that are common in all the experiments presented in the following sections. To show the effectiveness of the present cutting force estimation scheme, total 40 cutting tests are conducted with 5 and 8 different values of feedrate and radial depth of cut, respectively, as shown in Table 3 .

\subsection{Cutting Conditions for the Identification of the Prediction Model}

The cutting force prediction model shown in Eq. (5) is identified by conducting straight side milling tests in total 10 conditions (with different values of feed per tooth and radial depth of cut) on a response surface of the maximum undeformed chip thickness, $t_{m}$, and the arc length of cutting engagement, $L$. By measuring cutting forces in each test by using a tool dynamometer, six coefficients in Eq. (5) can be identified by using the least square method. 


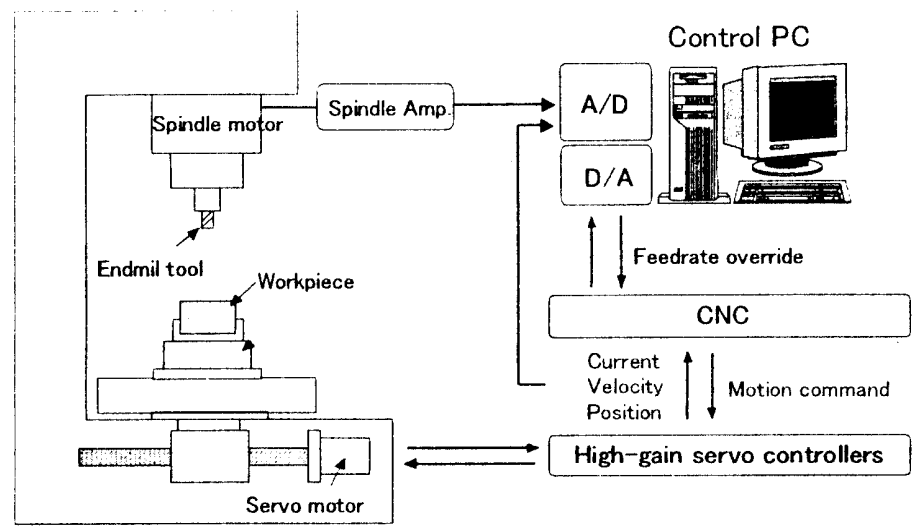

Figure 3 Experimental setup

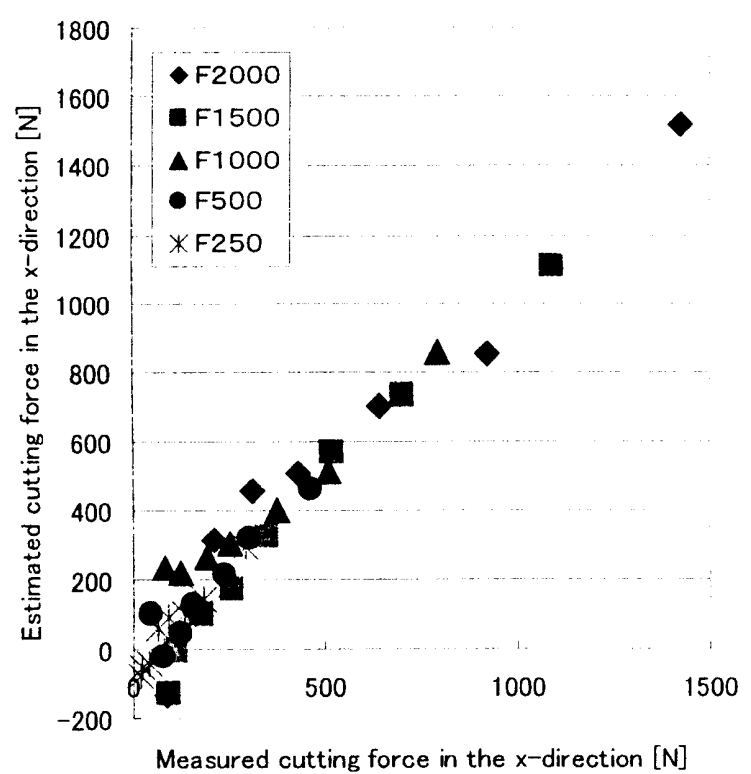

(a) Cutting forces in the $\mathrm{X}$-direction, $F_{x}$

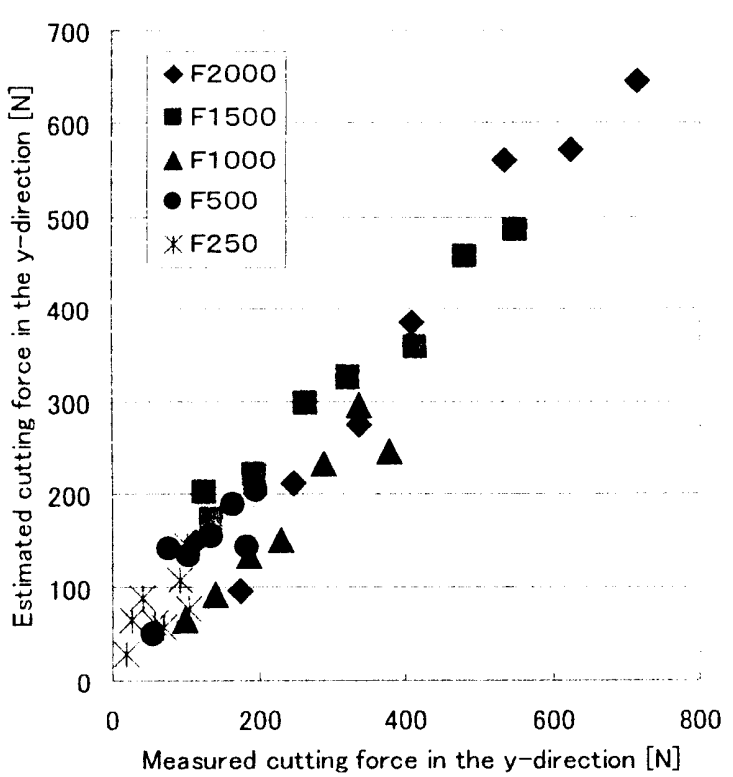

(b) Cutting forces in the Y-direction, $F_{y}$

Figure 4 Comparison between estimated cutting forces by servo and spindle motors and measured cutting forces by a tool dynamometer

\subsection{Cutting Conditions for Adaptive Control Tests}

Figure 3 overviews the experimental setup used in adaptive control experiments. The cutting force is monitored on-line by using internal sensors. We investigate by cutting experiments the effectiveness of regulating the cutting force to reduce the inclination of the finished surface. It validates the effectiveness and reliability of the cutting force control even under the progress of tool wear.

\section{Experimental Results and Discussion}

\subsection{Monitoring of Cutting Forces}

An estimate of the cutting torque, $T_{s p}$, is computed from the spindle motor current, and is compared with the cutting torque, $T_{t}$, measured by a tool dynamometer. By using the least square method, their relationship for every different combination of the feedrate and the radial depth of cut shown in Table 3 can be approximated by:

$$
T_{s p}=-0.002+1.264 \cdot T_{i}
$$

with the multiple correlation coefficient. $R$. of 0.996 . Note that the cutting torque, $T_{t}$, is computed from measured cutting forces by using the following equation (see Figure 1):

$$
T_{i}=r / 1000 \times F_{\mathrm{rr}} \times \cos \left(\cos ^{-1}\left(F_{\mathrm{r}} / F_{\mathrm{rr}}\right)-\alpha_{\mathrm{in}}\right)
$$

The cutting force in the non-moving axis direction. $/ \%$. can be estimated by using Eqs. (2). Figure 4 (a) 


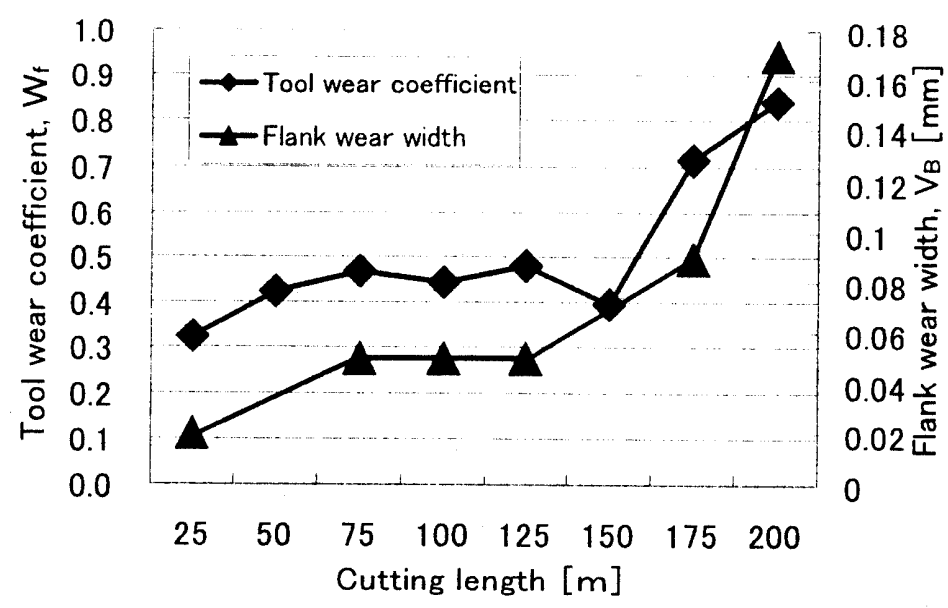

Figure 5 The tool wear coefficient and the flank wear width versus the cutting length

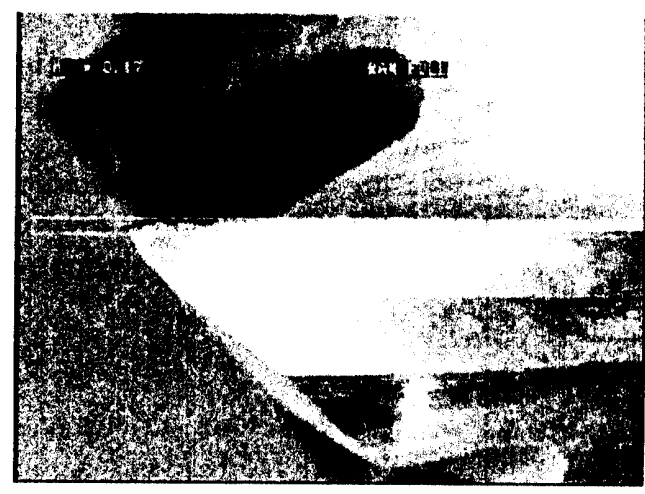

(a) At a tool tip (wear width $=0.17 \mathrm{~mm}$ )

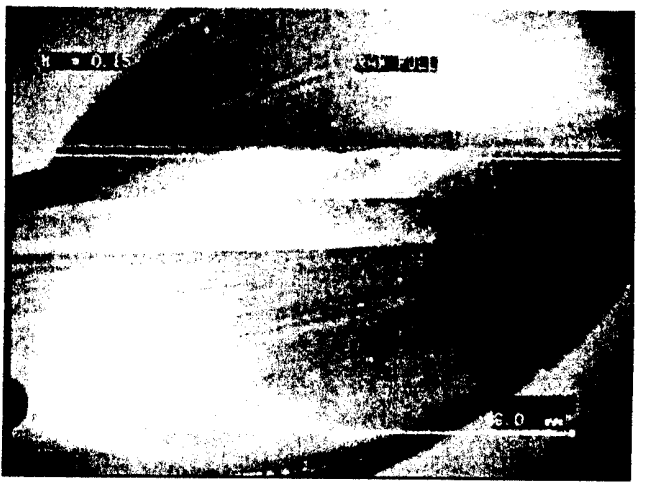

(b) At a boundary (wear width $=0.15 \mathrm{~mm}$ )

Figure 6 Tool wear at the feed distance of $200 \mathrm{~m}$

compares measured and estimated cutting forces in the non-moving axis direction. Figure 4 (b) shows estimated cutting forces in the moving axis direction, $F_{y}$, which is estimated by monitoring the y-axis motor current only.

Both cases show a good linear relationship between measured and estimated values. When the radial depth of cut, $R_{d}$, is $1.0 \sim 3.0 \mathrm{~mm}$, the error is $100 \mathrm{~N}$ at maximum. When $R_{d}$ is smaller than $1.0 \mathrm{~mm}$, the error becomes larger than $100 \mathrm{~N}$ in some cases. An overall estimation error in these tests was about $140 \mathrm{~N}$ at maximum.

\subsection{Identification of the Cutting Force Prediction Model}

By measuring cutting forces in machining tests, six coefficients, $C_{i j}$, in the cutting force prediction model can be identified by using the multiple regression analysis. For all models to respectively predict $F_{t r}, F_{t}$, and $F_{n}$, the adjusted coefficient of determination, $\hat{R}_{2}$, is larger than 0.9 , which validates the statistical reliability.

\subsection{Identification of the Prediction Model with a Consideration of Tool Life}

Prior to adaptive control tests, we conducted tool life tests to observe an increase in cutting forces with the progress of tool wear, and to identify the model given in Eq. (6). All the machining tests were conducted with the feedrate of $1120 \mathrm{~mm} / \mathrm{min}$, and the radial depth of cut of $1.0 \mathrm{~mm}$.

As the cutting length progresses, the tool wear coefficient, $W_{t}$, which is computed based on Eq. (6), increased as shown in Figure 5. When the feed distance exceeded $175 \mathrm{~m}$, sparks was observed. At the feed distance of $200 \mathrm{~m}$, the wear width at the tool tip became $0.17 \mathrm{~mm}$. and the boundary wear width became $0.15 \mathrm{~mm}$. At this point. we judged that the end of tool life was reached. By substituting the cutting force on the X-Y plane. $l_{r y}$, into Eq. (6), we have the tool wear coefficient, $W_{f}$, of 0.85 at this point.

At this point. in order to regulate the cutting force at the initial level (as will be shown in the following section), the feedrate must be reduced to $42 \mathrm{~mm} / \mathrm{min}$. Since it is about $1 / 27$ of the initial feedrate, it sacrifices the productivity too much. From the viewpoint of productivity as well. we judge that the tool must be ex- 
changed at this point. Figure 6 shows the tool wear at the tool tip and the boundary observed by a CCD camera at this time.

\subsection{Adaptive Control Accuracy}

One of the most critical factors to determine the inclination of the finished surface after side milling is the cutting force acting on the tool. Straight side milling tests are conducted with the feedrate optimized to regulate the cutting force at a constant level. By measuring the inclination of the finished surface, the effectiveness of the cutting force regulation to improve machining accuracies is validated.

A worn tool was used in order to show the effectiveness of the present feedrate optimization scheme even under the progress of tool wear. In a preliminary machining test with this worn tool, the measured cutting force was $F_{x y}=466 \mathrm{~N}$ with the feedrate of $1,120 \mathrm{~mm} / \mathrm{min}$, while it was $349 \mathrm{~N}$ with a new tool in exactly the same machining conditions. Therefore, from Eq. (6), the tool wear coefficient is given by:

$$
W_{t}=F / F_{n e w}-1=466 / 349-1=0.335
$$

Therefore, the target level to regulate the actual cutting force at the initial level is given by:

$$
F_{n e w} /\left(1+W_{f}\right)=261 \mathrm{~N}
$$

From the geometrical relationship illustrated in Figure 2, the optimal feedrate for the worn tool can be computed as $628 \mathrm{~mm} / \mathrm{min}$, while it is $1,120 \mathrm{~mm} / \mathrm{min}$ for the new tool.

The inclination of the finished surface, measured by using an electronic micrometer, after the straight side milling by the worn tool was about $2 \mu \mathrm{m}$. When this adaptive control accuracy was not performed (i.e. the feedrate was constant at $1,120 \mathrm{~mm} / \mathrm{min}$ ), the inclination of the finished surface by the worn tool was $10 \mu \mathrm{m}$, which validated the effectiveness of the adaptive cutting force control to improve the machining accuracy

\section{Conclusion}

The conclusions of this paper are as follows:

(1) We proposed an estimation method of cutting forces, $F_{x}, F_{y}$, and $F_{x y}$, based or motor currents of spindle and servo motors and the cutting engagement angle.

(2) The effectiveness of the proposed monitoring scheme was verified by preliminary machining tests on straight side milling to the $+y$ direction. The estimation error was about $140 \mathrm{~N}$ at maximum.

(3) On continuous machining tests on carbon steel S50C, it was verified that the end of tool was reached when the cutting force increased by $85 \%$ due to the tool wear.

(4) By regulating the cutting force at a constant level based on the proposed cutting force monitoring scheme, the inclination of the finished surface was significantly reduced.

References

(1) Y. Tang, W. Wang, Y. Kakino, I. Yamaji, T. Sato, and H. Ohtsuka, "Optimization of Slot End-Milling Process by Fixed Cycle Analysis for Die/Mold Machining," Proc. of the th JSME Manufacturing and Machine Tools Division Anmual Meeting, 2002.

(2) Y. Fujita, Y. Tang, W. Wang, Y. Kakino, I. Yamaji, H. Saraie, and H. Otsuka, "Intelligent End Milling Process Planning (1 st Report) - Process Planning for Trochoid Canned Cycles -," Proc. of the 2002 Fall JSPE Semiannual Meeting, 2002, pp. 208 (in Japanese).

(3) Y. Kakino, A. Matsubara, I. Yamaji, H. Saraie, M. Fujishima, H. Ohtsuka, and H. Nakagawa, "Intelligent Endmilling System and Its Application to Internal Cylindrical Machining with Spiral Curves," Proc. of 2002 JUSFA02, vol. 1 (2002), pg. 415-420.

(4) Y. Kakino, H. Ohtsuka, H. Nakagawa, T. Hirogaki, and M. Sasaki, "A Study on Endmilling of Hardened Steel (1st Report) -- Simplified Prediction Model for Cutting Forces and Control for Constant Cutting Forces Using this Model --," J. of the Japan Society for Precision Engineering, Vol.66, No.5 (2000), pp.730-734 (in Japanese).

(5) H. Otsuka, Y. Kakino, A. Matsubara, H. Nakagawa, and T. Hirogaki, "A Study on Endmilling of Hardened Steel (2nd Report) -- Control for Constant Cutting Forces in Comer Profile Endmilling Including Connection Areas of Tool Paths --," J. of the Japan Society for Precision Engineering, Vol.67, No.8 (2001), pp.1294-1298. 